\title{
Major 2017 Hurricanes and their Cumulative Impacts on Coastal Waters of the USA and the Caribbean
}

\author{
Anna Wachnicka ${ }^{1} \cdot$ Anna R. Armitage ${ }^{2} \cdot \operatorname{lan}$ Zink $^{3,4} \cdot$ Joan Browder $^{4} \cdot$ James W. Fourqurean $^{5}$
}

Received: 16 December 2019 / Revised: 6 January 2020 / Accepted: 7 January 2020 / Published online: 16 January 2020

(C) Coastal and Estuarine Research Federation 2020

Hurricanes are natural disturbance events that can cause extensive damage to coastal infrastructure and result in major alterations of water quality, biogeochemistry, and ecological conditions in coastal regions and estuaries. These damages occur in response to hurricane-associated strong winds (maximum sustained winds can exceed $252 \mathrm{~km} / \mathrm{h}$ ), storm surges, heavy rainfall, flooding, and storm water runoff. Analyses of global hurricane data indicate a 30-year trend toward more intense and frequent hurricanes, which is likely linked to global climate change (Emanuel 2005; Webster et al. 2005; Balaguru et al. 2018; Bhatia et al. 2019). Understanding the impacts of individual hurricanes and cumulative impacts of recurring hurricanes on the resilience and resistance of coastal and estuarine systems is essential for natural systems management (Pruitt et al. 2019). This is especially true in regions where extensive urbanization has resulted in highly managed natural systems (e.g., in the Everglades). Extreme disturbances can easily postpone, halt, or even reverse these efforts (Morrison et al. 2006; Paerl et al. 2006, 2018). Therefore,

Communicated by Paul A. Montagna

Communicated by Paul A. Montagna

Anna Wachnicka

awachnic@sfwmd.gov

1 Applied Science Bureau, South Florida Water Management District, 3301 Gun Club Rd, West Palm Beach, FL 33406, USA

2 Department of Marine Biology, Texas A \& M University at Galveston, PO Box 1675, Galveston, TX 77553, USA

3 Rosenstiel School of Marine and Atmospheric Science, University of Miami, 4600 Rickenbacker Causeway, Miami, FL 33149, USA

4 Southeast Fisheries Science Center, National Oceanic and Atmospheric Administration, 75 Virginia Key Dr, Miami, FL 33149, USA

5 Center for Coastal Oceans Research, Department of Biological Sciences, Florida International University, 11200 SW 8th St, Miami, FL 33199, USA knowing how natural and human-altered systems respond to natural disturbances can help to formulate appropriate strategies for ecosystem restoration and management in the systems affected by more frequent and intense natural disturbances.

The 2017 hurricane season in the North Atlantic Basin was the most active since 2005 and the seventh most active since the beginning of consistent hurricane data recording in 1851 (NOAA 2017). A total of seventeen named storms formed in this Basin in 2017, ten of which became hurricanes and six became major hurricanes (category 3 or higher; NOAA 2017). Three of the major hurricanes had particularly devastating ecological and human tolls, with pronounced impacts on the coasts of Texas (Hurricane Harvey: Blake and Zelinsky 2018), the southeastern USA (Hurricane Irma: Cangialosi et al. 2018), and several Caribbean islands, including the US Virgin Islands and Puerto Rico (Hurricanes Irma and Maria: Pasch et al. 2019; Fig. 1).

This special issue contains scientific papers describing the effects of hurricanes Harvey, Irma, and Maria and/or the cumulative impacts of multiple 2017 hurricanes on coastal and estuarine systems in the Caribbean and the Gulf and South Atlantic coasts of the USA, including coral reef, seagrass, mangrove, marsh, and coastal upland habitats. The studies span trophic levels ranging from primary production up to apex predators, and many examined the impact of hurricanes on coastal management efforts. These papers incorporate the concepts of ecosystem resistance, resilience, and restoration into synergistic discussions relevant to resource managers, policymakers, governmental entities, practitioners of restoration, and academics. These studies are timely in that there has been an explicitly stated call for further study and deeper understanding of hurricane impacts on ecosystems as well as management responses to those impacts (Pruitt et al. 2019).

Information presented in this special issue improves our understanding of the resistance and resilience of natural and humanaltered coastal and estuarine ecosystems to natural disturbances. Readers can find ideas about strategies and opportunities for ecosystem-based coastal protection and management in coastal 


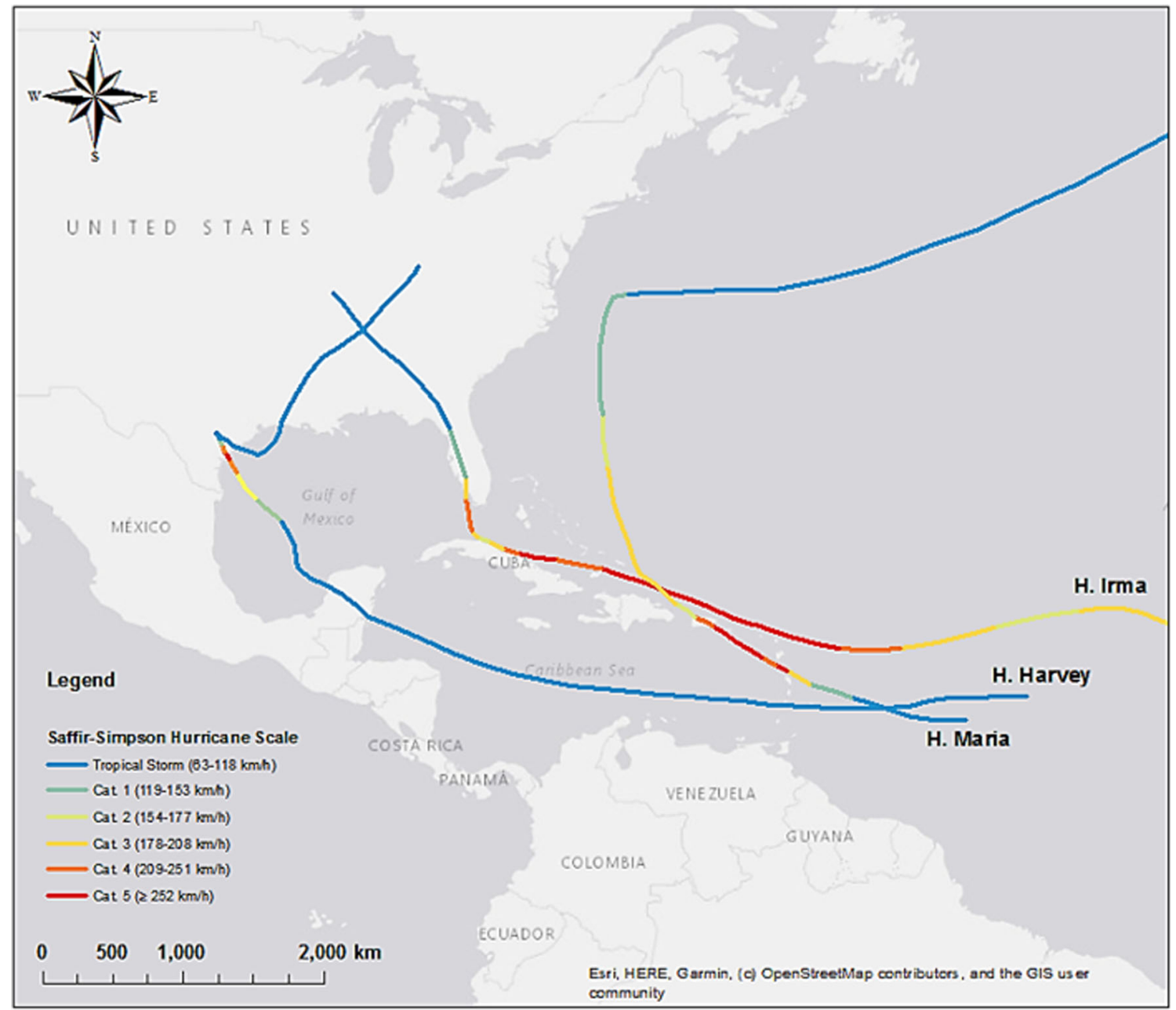

Fig. 1 Tracks of the three major hurricanes (Harvey, Irma, and Maria) which devastated the Caribbean and the coastal regions of the USA in 2017. The colors represent the storms' maximum sustained wind speeds as classified in the Saffir-Simpson hurricane scale

regions that are prone to hurricanes. This issue also provides insight into how ecological restoration can improve resilience and/or resistance to extreme perturbations such as hurricanes.

\section{References}

Balaguru, K., G.R. Foltz, and L.R. Leung. 2018. Increasing magnitude of hurricane rapid intensification in the central and eastern tropical Atlantic. Geophysical Research Letters 45 (9): 4238-4247.

Bhatia, K.T., G.A. Vecchi, T.R. Knutson, H. Murakami, J. Kossin, K.W. Dixon, and C.E. Whitlock. 2019. Recent increases in tropical cyclone intensification rates. Nature Communications 10 (1): 635.

Blake, E.S., and D.A. Zelinsky. 2018. Hurricane Harvey. National Hurricane Center Tropical Cyclone Report. National Weather Service: NOAA.

Cangialosi, J.P., A.S. Latto, and R. Berg. 2018. National Hurricane Center tropical cyclone report: Hurricane Irma. National Oceanic and Atmospheric Administration.

Emanuel, K. 2005. Increasing destructiveness of tropical cyclones over the past 30 years. Nature 436 (7051): 686-688.

Morrison, G., E.T. Sherwood, R. Boler, and J. Barron. 2006. Variations in water clarity and chlorophyll a in Tampa Bay, Florida, in response to annual rainfall, 1985-2004. Estuaries and Coasts 29 (6): 926-931.
NOAA. n.d. 2017 Atlantic hurricane season. Retrieved April 12, 2018, from https://www.nhc.noaa.gov/data/tcr/index.php?season= $2017 \&$ basin $=$ atl.

Paerl, H.W., L.M. Valdes, A.R. Joyner, B.L. Peierls, M.F. Piehler, S.R. Riggs, et al. 2006. Ecological response to hurricane events in the Pamlico sound system, North Carolina, and implications for assessment and management in a regime of increased frequency. Estuaries and Coasts 29 (6): 1033-1045.

Paerl, H.W., J.R. Crosswell, B. Van Dam, N.S. Hall, K.L. Rossignol, C.L. Osburn, et al. 2018. Two decades of tropical cyclone impacts on North Carolina's estuarine carbon, nutrient and phytoplankton dynamics: Implications for biogeochemical cycling and water quality in a stormier world. Biogeochemistry 141 (3): 307-332.

Pasch, R. J., Penny, A. B., \& Berg, R. (2019). National Hurricane center tropical cyclone report: Hurricane Maria. TROPICAL CYCLONE REPORT AL152017, National Oceanic And Atmospheric Administration and the National Weather Service, 1-48.

Pruitt, J.N., A.G. Little, S.J. Majumdar, T.W. Schoener, and D.N. Fisher. 2019. Call-to-action: a global consortium for tropical cyclone ecology. Trends in Ecology \& Evolution 34 (7): 588-590.

Webster, P.J., G.J. Holland, J.A. Curry, and H.R. Chang. 2005. Changes in tropical cyclone number, duration, and intensity in a warming environment. Science 309 (5742): 1844-1846. 